\title{
INTRODUÇÃO DA GLOSINAIS COMO FERRAMENTA DE TRADUÇÃO / INTERPRETAÇÃO DAS PESSOAS SURDAS BRASILEIRAS
}

\begin{abstract}
Dra. Profa. Ana Regina Campello - UFRJ - Professora e Doutora de Educação da UFSC. Atualmente, Professora de Libras, ministra disciplina de Pós Graduação Lacto Sensu na UFRJ e disciplina de Pós-Graduação Stricto Sensu do Estudo de Tradução na UFSC desde 2010. Tradutora e Intérprete de Libras e ASL (Língua de Sinais Americana)

Email: anarcampello@gmail.com
\end{abstract}

Mestre Prof. Nelson Pimenta de Castro-INES - Mestre em Estudos de Tradução pela UFSC e Professor do INES. Intérprete de ASL (Língua de Sinais Americana).

Email: npimenta@1sbvideo.com.br

\begin{abstract}
Resumo
$\mathrm{O}$ artigo como apresentação de um trabalho científico objetiva mostrar o processo histórico da nova ferramenta de tradução / interpretação dos tradutores / intérpretes Surdos no território brasileiro. A justificativa deste artigo é expor conhecimento acerca da ferramenta de tradução / interpretação pelos tradutores / intérpretes Surdos; mostrar o potencial da percepção visual; facilitar a compreensão por parte dos profissionais que lidam na tradução e interpretação; substituir o mecanismo de tradução / interpretação e, finalmente, oferecer outras oportunidades no mercado de trabalho dos futuros profissionais (intérpretes e tradutores Surdos de língua de sinais brasileira). O uso da metodologia, procedimento e instrumentos utilizados na pesquisa foram: experiência profissional; utilização da introdução do mecanismo de tradução / interpretação na gravação de vídeo acadêmico; criação de Glosinais; e finalmente as contribuições das experiências vividas dos autores que trabalharam como tradutores / intérpretes de duas línguas distintas (LSB e ASL).
\end{abstract}

\begin{abstract}
The article as presenting a scientific paper aims to show the historical process of the new tool translation / interpretation of translators / interpreters Deaf in Brazil. The rationale of this article is to expose knowledge of tool translation / interpretation by the translators / interpreters Deaf, show the potential of visual perception; facilitate understanding by professionals dealing in translation and interpretation; replace the mechanism of translation / interpretation and finally, offer other opportunities in the labor market of the future professionals (interpreters and translators Deaf Brazilian Sign Language). The use of the methodology, procedure and instruments used in the research were: professional experience, use the introduction of the mechanism of translation / interpretation in video recording academic; creating Glosinais, and finally the contributions of the experiences of the authors who worked as translators / interpreters two distinct languages ( ASL and LSB ).
\end{abstract}

\section{SIGLAS}

LSB - Língua de Sinais Brasileira

ASL - American Sign Language 


\section{1) Introdução}

O artigo, como apresentação de um trabalho acadêmico da Revista Escrita, objetiva mostrar o processo histórico da nova ferramenta de tradução / interpretação dos tradutores / intérpretes Surdos no território brasileiro.

A justificativa da apresentação deste artigo é:

a) expor conhecimento acerca da ferramenta de tradução / interpretação pelos tradutores / intérpretes Surdos;

b) mostrar o potencial da percepção visual;

c) facilitar a compreensão por parte dos profissionais que lidam na tradução e interpretação;

d) substituir o mecanismo de tradução / interpretação e,

e) oferecer outras oportunidades no mercado de trabalho dos futuros profissionais (intérpretes e tradutores de língua de sinais brasileira).

Destacamos, nesse contexto, a singularidade da língua em que os Surdos Brasileiros fazem no uso da Língua Brasileira de Sinais - LIBRAS como seu principal meio de reflexão e comunicação de expressão.

As conquistas legais da comunidade surda se concretizaram através da Lei da Acessibilidade, 10.048/00 e 10.098/00 na tradução / interpretação dos Intérpretes de Libras, Lei ${ }^{\circ} 10.436 / 2002$ pela qual a língua de sinais foi reconhecida e pelo Decreto $\mathrm{n}^{\mathrm{o}}$ 5.626/2005, que garantiu, dentre outros avanços, uma educação bilíngue (língua brasileira de sinais e língua portuguesa escrita), formação dos professores bilíngues e Intérprete de Libras, além da presença de intérprete na sala de aula em qualquer nível de escolaridade. Isso tudo serviu como um propulsor para o reconhecimento da profissão de intérprete da Língua Brasileira de Sinais no contexto nacional, assim como na formação deste nos Cursos Bacharelado de Letras-Libras.

A profissão de Tradutor / Intérprete de LIBRAS foi reconhecida pela Lei $\mathrm{n}^{\circ}$ 12.319/2010. A lei elaborou novas discussões, de modo contínuo, acerca dos parâmetros para o exercício de tal função, como a formação, atuação, performance, proficiência, sindicalização, associativa (para representar os profissionais - controle de quantidade / qualidade, carreira e salários - ou incentivar a criação de Associações) e valorização dessa atividade, já que o intérprete:

[...] processa a informação dada na língua fonte e faz escolhas lexicais, estruturais, semânticas e pragmáticas na língua alvo que devem se aproximar o mais apropriadamente possível da informação dada na língua fonte. Assim sendo, o intérprete também precisa ter conhecimento técnico para que suas escolhas sejam apropriadas tecnicamente. Portanto, o ato de interpretar envolve processos altamente complexos. (QUADROS, 2004, p.27). 
De acordo com Quadros (2004), a área de interpretação mais requisitada hoje é na área da educação, com o objetivo de promover a inclusão dos alunos surdos na rede pública e particular de ensino. Há outras áreas especificas como tradução / interpretação nos teatros, jornalismos televisivos, missas, eventos governamentais e muitos outros.

\section{1) Processo Linguístico}

A respeito da língua e sua tradução / interpretação, há dois processos linguísticos e culturais particulares, isto é, o da língua fonte e o da língua alvo. O intérprete de Libras - Língua Portuguesa - Libras é um conhecedor/especialista profundo das duas línguas em uso, sua cultura, com competência e ética profissional na área de tradução e interpretação. Essa competência está intrinsecamente relacionada a uma capacidade de compreensão e de adequação discursiva. Segundo Rosa (2005, p. 131):

Num sentido mais restrito, os conhecimentos adquiridos pelo intérprete (ou a sua cultura) the permitem selecionar alternativas translatórias, nos casos em que o contexto linguístico e o contexto situacional não sejam suficientes, porque, no ato tradutório, são atualizados horizontes de natureza ideológica, lógica, emocional e textual.

A fluência também está intrinsecamente relacionada a uma fluência linguística, como escreve os autores:

[ ] relativas às línguas orais, a fluência em língua de sinais poderia ser relacionada a um encadeamento harmônico entre os movimentos que compõem os sinais, pois se a fluência na fala é caracterizada pelo índice de velocidade, frequência e duração das pausas (TROFIMOVICH E BAKER, 2006, apud PIRES, s/d).

O intérprete de LIBRAS tem a obrigação de exercer sua profissão com ética e respeito e com o máximo de qualidade e responsabilidade, já que está intermediando a plena garantia de comunicação, acesso à informação e educação de uma pessoa Surda.

\section{2) Formação do profissional intérprete}

Apesar da legislação que reconhece tal profissão desde 2010, a atuação do intérprete no Brasil, na década de 80, era como uma atividade voluntária (QUADROS, 2004), pelo fato das pessoas que envolveram juntos com os Surdos, no caso dos professores bilíngues, filhos de pais Surdos, e simpatizantes que vem sensibilizando com as dificuldades enfrentadas pelos Surdos. Assim, os mecanismos para a inclusão destas pessoas na comunidade Ouvinte têm sido pensados pelas organizações não governamentais com o intuito de contribuir para a democratização do ato de se comunicar e de ser compreendido. É impossível deixar de repensar que os anos de experiência e de uso da língua de sinais brasileira proporcionaram, aos poucos, a 
construção linguística e empírica de paradigmas fundamentais para o processo de sua profissionalização.

A formação do tradutor / intérprete de LIBRAS, de acordo com a Lei, e o uso da função se relaciona com a formação de nível médio. E para adquirir conhecimento para adequar no ensino universitário, os futuros Intérpretes devem participar dos cursos de tradução / interpretação profissional reconhecido pelo sistema credenciado e reconhecido; cursos de extensão universitária; e cursos de formação continuada, promovidos por instituições de ensino superior e instituições credenciadas pelo MEC Ministério da Educação ou por intermédio de organizações da sociedade civil representativas da comunidade surda.

No entanto, a supressão do Decreto $n^{\circ} 5.626 / 05$ que antecede a Lei na formação desse profissional em nível superior, a comunidade Surda luta pela distinção de dois cargos: Intérprete de Libras no nível superior (cargo denominado de E) e Intérprete de Libras no nível médio (cargo denominado de D) pela justificativa da designação do cargo de tradutor e intérprete de libras como um cargo distinto do de tradutor e intérprete de línguas.

Hoje, no Brasil, a formação do intérprete de língua de sinais já tem ocorrido tanto em nível médio quanto por meio de curso superior em formato de Graduação ou Pós-Graduação Lato Sensu. Como exemplo de iniciativa governamental do modelo proposto em nível superior, citamos o curso de Bacharelado em Letras-Libras, oferecido pela Universidade Federal de Santa Catarina - UFSC, e o curso de Especialização em LSB: Ensino, Tradução e Interpretação, promovida pela Universidade Federal do Rio de Janeiro - UFRJ. Entretanto, se pensarmos em escala nacional, esse tipo de curso ainda é muito escasso.

É importante refletir que um curso de formação de intérprete difere de um curso de LSB comum. Em geral, os participantes já possuem um bom nível de fluência da língua brasileira de sinais. Durante o curso, é esperado que o profissional em formação aprofunde seu conhecimento teórico de diversas temáticas relacionadas à LSB, além de atingir uma maior fluência nas duas modalidades linguísticas em questão e de desenvolver técnicas de tradução/interpretação.

Igualmente, o perfil e o exercício do papel de Intérprete de Língua de Sinais Brasileira não são exclusivamente de pessoas ouvintes. As pessoas Surdas podem exercer esta função nos serviços de interpretação / tradução e transliteração da língua de sinais brasileira e outro tipo de comunicação visual e tátil (utilizado pelas pessoas SurdasCegas). Como pessoa Surda, o Intérprete Surdo começa com um conjunto distinto de experiências linguísticas, culturais e de vida que permite a compreensão e conhecimento diferenciado e interação em uma ampla gama de recursos visuais e formas de comunicação influenciadas pela região, de contato, cultura, idade, alfabetização, nível de fluência, educação, saúde, classe social, físico, cognitivo e mental. Estas experiências, juntamente com a formação profissional, dão ao Intérprete 
Surdo a capacidade de efetuar uma comunicação bem-sucedida em todos os tipos de interações interpretadas, das quais:

a) da rotina, que condiz a realização, a partir do uso da Língua Brasileira de Sinais, a interpretação / tradução para surdocegos usuários ou repassa as informações em Língua de Sinais tátil quando a língua fonte estiver em LSB e vice versa; realizar a comunicação com surdos usuários de diferentes línguas de sinais oriundos de diversos países, em eventos internacionais; realizar a interpretação simultânea ou consecutiva entre a Língua Brasileira de Sinais e o português, da modalidade escrita e vice versa, em relacionamentos pessoais, comerciais e de trabalho, bem, como nos diversos serviços de atendimento ao público; traduzir / interpretar palestras, aulas e discursos em LSB, principalmente no ambiente escolar; demonstrar habilidades de produção e de recepção do discurso oral e escrito em língua portuguesa, bem como aspectos da cultura brasileira e regional, utilizando a competência comunicativa; recepcionar turistas, clientes e visitantes da língua estrangeira sinalizada; informar, em sinais, sobre roteiros turísticos, clima, serviços turísticos e meios de hospedagem; atender chamadas telefônicas, solicitações e reclamações, através de sinais; preencher formulários, obter e transmitir informações inerentes e, finalmente, realizar leitura de textos informativos, literários e manuais técnicos, além de produzir textos em sinais.

b) de alto risco, que condiz a preocupação de, além da fluência em Língua Brasileira de Sinais, de possibilitar a comunicação em LSB com pessoas surdas usuárias da LSB, com desinibição corporal em diversos contextos sociais, principalmente no contexto escolar, de modo conciso e claro; dominar ou possuir o conhecimento prévio da Língua Brasileira de Sinais para a comunicação; tratar o interlocutor de acordo com o grau de formalidade adequada ao contexto, informar horários, preços e descrever rotina pessoal, de trabalho e escolar e, finalmente e o mais importante é entender os conceitos para que a tradução / interpretação possa garantir ao cliente / usuário surdo o acesso ao conteúdo.

Os estudos norte-americanos e brasileiros indicam que, em muitas situações, o uso de Intérprete Surdo permite um nível de linguística, de comunicação e de cultura de transição que muitas vezes não é possível de ser captado pelos Intérpretes ouvintes, quando trabalham sozinho junto com as pessoas Surdas.

Atualmente, os Intérpretes Surdos trabalham nos eventos em que há o uso da língua estrangeira, no caso de Língua de Sinais Americana e algumas vezes, junto com o Intérprete ouvinte, em que há dificuldade no entendimento e na compreensão da comunicação das pessoas Surdas. 


\section{2) Metodologia}

Indicamos a Pesquisa Experimental, que constitui e envolve algum tipo de experimento. $\mathrm{O}$ objetivo primordial é mostrar a importância da introdução de uma nova modalidade nos moldes do Stone (2009) e concluímos que a produção de dados que foram: transcrição da língua alvo e da utilização do mecanismo, que é o Glosinais, que será apresentado logo em outros parágrafos, em tempo real. A metodologia, procedimento e instrumentos utilizados na pesquisa:

- experiência profissional através dos tradutores / intérpretes nos eventos em 2010;

- utilização da introdução do mecanismo de tradução / interpretação na gravação de vídeo acadêmico na disciplina do Seminário de Tradução / Interpretação em 2011. Desde então surgiu a Glosinaisis;

- aproveitamento do mecanismo de tradução / interpretação às pessoas Surdas iletradas, funcionais e fluentes em língua de sinais brasileira em janeiro de 2012;

São as experiências vividas dos autores que trabalharam como tradutores / intérpretes de duas línguas distintas (LSB e ASL), segundo a afirmação do autor:

Dentro de uma perspectiva breve de conceituação o saber é entendido como o ato de ter ou incorporar conhecimento de algo, quer seja em nível teórico quanto em nível prático. Assim, o saber passa a ser resultado de uma intervenção do homem em sua forma de produção da existência e/ou de sua idéia sobre a mesma e das manifestações dos fenômenos que privilegia, segundo a valoração e grau de importância que emprega ao objeto do conhecimento. Os saberes que o homem tem construído ao longo de sua existência e transmitido às gerações posteriores correspondem ao desenvolvimento de seu universo cultural (em nível de processo de transformação de sua produção) e, de forma indissociável, aos avanços científicos e tecnológicos que explicitam as rupturas e permanências de um conhecimento que não é (acabado), mas que está (em construção). Os saberes pedagógicos por sua vez correspondem à dimensão dos conhecimentos teórico-práticos construídos a partir de um olhar historicamente situado do homem (LIMA, 2010, p. 9).

Os materiais básicos foram utilizados como: filmadora, texto científico e utilização de dois tradutores/atores de língua de sinais brasileira. Não foi necessária a utilização de glosas ${ }^{\text {ii }}$. Essa forma de tradução utiliza, em vez de glosas em português na tela, um vídeo com sinalização para que se 'reinterprete' em mesma língua (Língua de Sinais Brasileira). Sendo que a primeira tarefa será assumida pelo primeiro tradutor bilíngue que consiste a leitura textual da língua fonte, no caso da língua portuguesa, e depois sinaliza atrás da filmadora que fica em frente do segundo tradutor / intérprete que assimila ou copia a mesma tradução da língua alvo em língua de sinais brasileira, ou seja, língua da modalidade sinalizada. Aprender a fazer, no e para o espaço de tradução / interpretação, consiste numa reflexão da realidade, extraindo-lhe as informações necessárias para uma intervenção sistematizada e intencional por meio dos mecanismos mais apropriados e coerentes com as necessidades da tradução / interpretação pelos 
tradutores / intérpretes e segue o desenvolvimento que culminou o novo mecanismo chamado de Glosinais, em vez de Glosa, pelo Stone (2009).

\section{3) Desenvolvimento}

A experiência profissional através dos tradutores / intérpretes se deu no evento chamado "I Encontro dos Alunos Surdos de ASL - Língua de Sinal Americana", realizada em Uberlândia (MG), no auditório oferecido pela Universidade Federal de Uberlândia, nos dias 5 e 6 de setembro de 2010.

A tradução e a interpretação da modalidade intralingual sinalizada em língua de sinais brasileira visualizada em língua de sinais brasileira visualizada, que para Roman Jakobson, existem três tipos de tradução: 1) A tradução intralingual, ou reformulação, que consiste na interpretação dos signos verbais por meio de outros signos da mesma língua; 2) A tradução interlingual, ou tradução propriamente dita, que consiste na interpretação dos signos verbais por meio de alguma outra língua e; 3) A tradução intersemiótica, ou transmutação, que consiste na interpretação dos signos verbais por meio de sistemas de signos não-verbais (1975: 64-5). Portanto o primeiro item desses confere suporte e novo procedimento brasileiro. Sobre o tipo de tradução utilizada por tradutores surdos a diferentes formas de serem realizadas, atualmente há alguns estudos que analisam o recurso de ver uma sinalização em uma tela produzindo outra, sendo assim uma forma de glosa intralingual. Esse termo foi utilizado pela primeira vez por Castro (2012, p.41) em sua dissertação inovadora toda realizada em língua de sinais em vídeo, este menciona que após a obtenção da versão final da dissertação traduzida para o português, o tradutor lê em LSB atrás da câmera para seja feita a reinterpretação e a própria produção em língua de sinais. Esta forma de se fazer glosa para tradução é recente e abre um vasto campo para pesquisas. Entretanto como veremos na metodologia deste trabalho a forma de glosa utilizada pelo surdo para a sinalização do vídeo a ser interpretada foram glosas em português. Mas, pela experiência idêntica, esta técnica, nos eventos nacionais e internacionais, já foi utilizada como "reinterpretação" para evitar o "mau jeito" ou da "poluição visual" do campo visual dos participantes como palestrantes na mesa principal que presenciam os intérpretes das duas línguas (LSB e ASL) que ficam em dois lados diferentes e posições em frente dos palestrantes ou participantes. Se as técnicas não forem utilizadas, a tensão na hora de presenciar, os intérpretes / tradutores, de modo desconfortável, e da posição da cadeira e do ritmo das interpretações desenvolvidas durante o dia, os músculos do pescoço e costas podem afetar ou trazer surpresas desagradáveis como perda das informações.

Para evitar esse problema, foi introduzido o novo mecanismo que é a "reinterpretação", que consistem as duas posições dois intérpretes Surdos, sendo que o 
primeiro intérprete que fica sentado em frente de um palestrante Surdo e "reinterpreta" em língua de sinais brasileira e repassa com a mesma informação ao segundo intérprete que fica em pé ao lado de um palestrante sinalizante ${ }^{\mathrm{iii}}$, como mostra a figura abaixo.

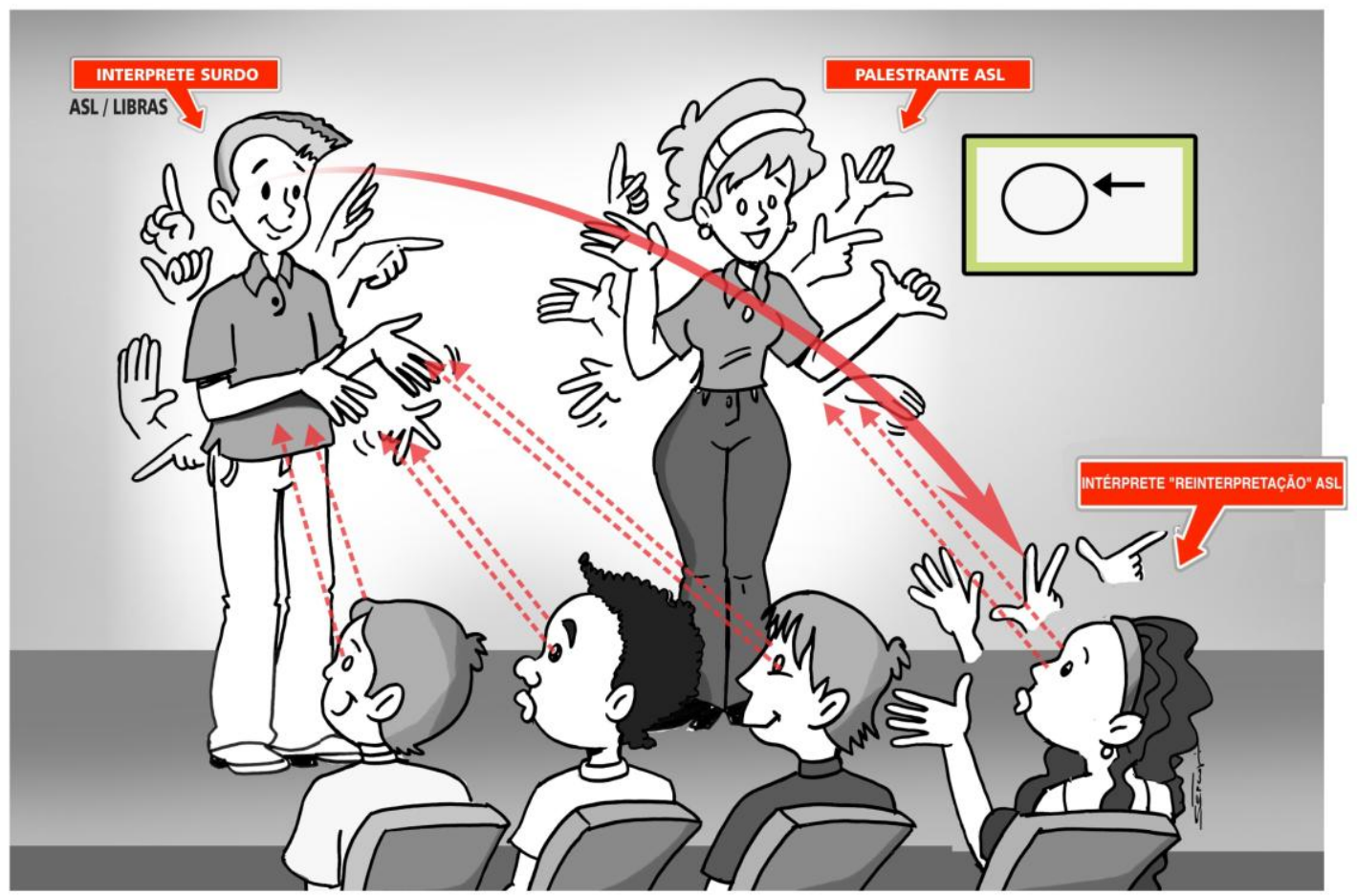

Figura 1

O mecanismo "reinterpretação" é o indício de um novo caminho de interpretação / tradução intralíngual, pois facilita, e ao mesmo tempo em que beneficia uma melhor visualização, dos conceitos, da compreensão e do esclarecimento dos sinais dentro do campo visual.

\section{1) Mecanismo}

Em 2011, durante a disciplina chamada de "Seminário de Pesquisa de Língua de Sinais", oferecida no Curso de Estudos de Tradução, da Universidade Federal de Santa Catarina, os Professores Dr. Markus Johannes Weininger e Dra. Ronice Muller Quadros determinaram a publicação de um artigo, e os autores se viram a impossibilidade de cumprir em curto tempo com a publicação de um vídeo.

Como a utilização de glosa, que é um dos recursos muito utilizados na tradução / interpretação acadêmica do Curso de Letras - LSB, modalidade Ensino a Distância, não propiciava ajuda e acabamos de criar o novo mecanismo de tradução / interpretação na 
gravação de vídeo acadêmico nesta disciplina que é a Glosinais. Para melhor entendimento, muitos tradutores Surdos que, quando viam ou liam a língua portuguesa em glosa através de teleprompter ${ }^{\text {iv }}$ sinalizavam em língua aportuguesada ${ }^{v}$ de sinais e perdia essência da tradução da língua de sinais brasileira. O mecanismo do Glosinais requer a presença de uma tradutora, na execução da sua atividade tradutória, ficava atrás da câmera de filmadora, lia o texto em língua portuguesa escrita e repassava as informações para língua de sinais brasileira e o Surdo "reinterpreta" as mesmas informações através da língua de sinais brasileira repassada pela tradutora, como mostra a figura abaixo.

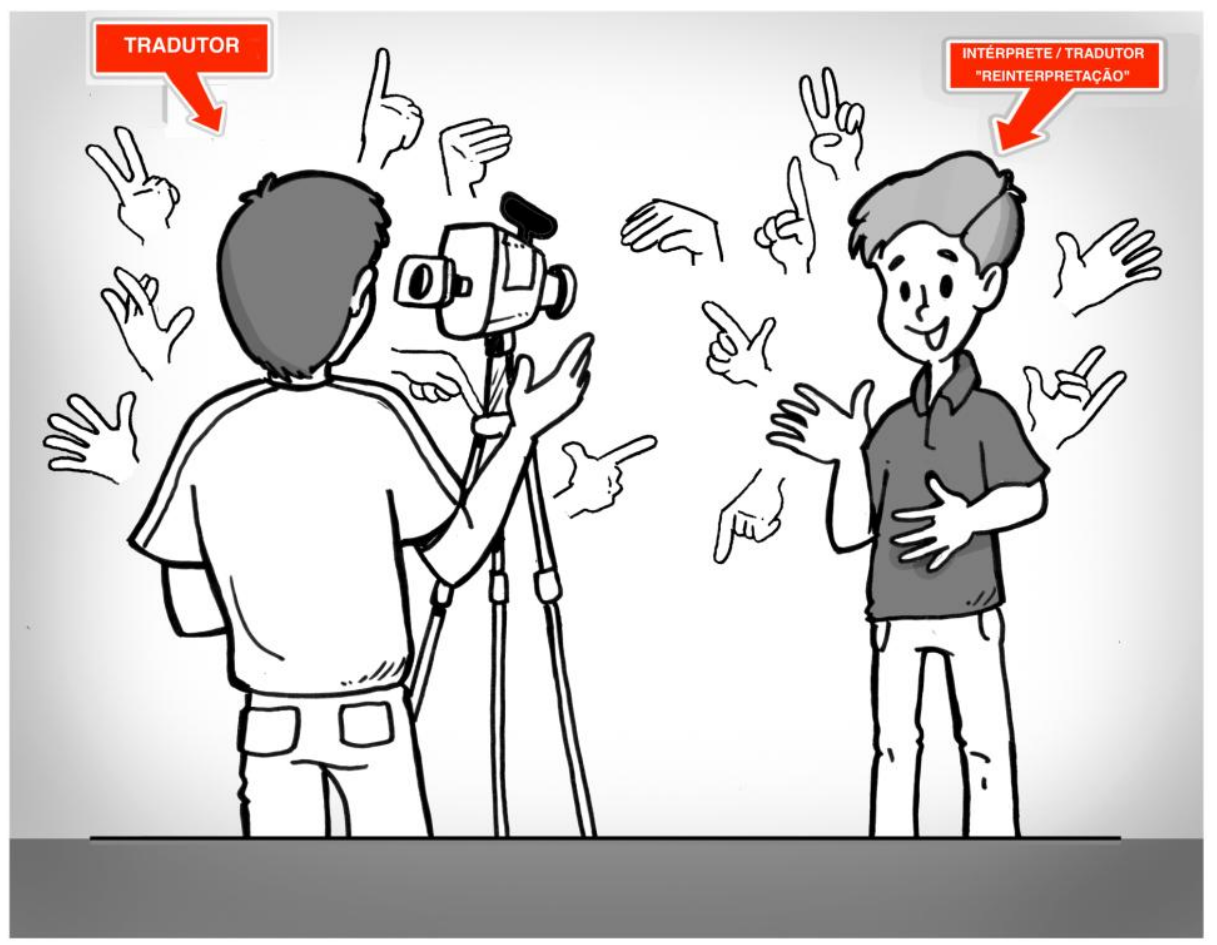

Figura 2

Esta é uma das reflexões que possibilitou o melhor aproveitamento e uso deste mecanismo de glosinais na tradução / interpretação às pessoas Surdas iletradas, funcionais e fluentes em língua de sinais brasileira realizada em Maceió (Alagoas), no mês de janeiro de 2012, promovida pela AAPPE - Associação dos Amigos e Pais de Pessoas Especiais.

Inicialmente, os atores Surdos iletrados e funcionais da língua portuguesa, mas fluentes em língua de sinais brasileira, durante as filmagens da produção de um novo vídeo (DVD) no projeto chamado "Projeto Audição Sem Mistério" que consistia as distribuições de DVDs à comunidade Surda de Alagoas com o objetivo de conhecer os folclores da cultura alagoana em língua de sinais brasileira. 
Os atores Surdos, que têm pouco contato da língua portuguesa como segunda língua, tinham dificuldade de entender o texto da língua portuguesa para que possam exercer na sua atividade tradutória para a língua portuguesa. O diretor ouvinte / sinalizante, elaborou o roteiro do folclore de Alagoas, em língua portuguesa e transformou em glosa escrita em língua portuguesa. Em seguida, distribuiu aos atores e os mesmos não entendiam cada palavra da língua portuguesa e o diretor sinalizante passou a traduzir o glosa escrito em língua de sinais brasileira. Os mesmos ainda continuavam tendo essas dificuldades porque o diretor sinalizante expressava a mesclagem da língua de sinais brasileira em língua aportuguesada. A partir de então, o diretor sinalizante passou a repassar as mesmas informações, conforme com a glosa escrita da língua portuguesa, em língua aportuguesada mesclada em língua de sinais brasileira ao tradutor Surdo e esse repassava em língua de sinais brasileira nativa aos atores Surdos. O mecanismo glosinais ajudou muito aos atores Surdos a entenderem melhor a primeira língua de sinais brasileira e nativa pelo tradutor Surdo.

Do mesmo modo em relação do entendimento da língua como primeira língua na transmissão de informação, no caso da língua portuguesa, esse procedimento se reflete com uma atriz da Globo, Isabela Garcia, que não conseguia decorar a língua portuguesa, através da memorização (o que é usualmente é exigida através do treinamento auditivo para obter a memorização ou decorar as "falas" e depois repassar as "falas" de acordo com o texto da qual interpretará o personagem), no ato da interpretação da gravação de um documentário da AAPEE e exigia constantemente o uso de teleprompter que aliviava a sua interpretação do papel como apresentadora em que sucumbia, lendo a língua portuguesa da modalidade escrita. E a atriz Jacqueline Laurence tinha grandes dificuldades de decorar o texto e se recusava a usar ponto eletrônico em um dos ouvidos. Para não perder a "fala", um funcionário da emissora teve que ficar lendo em voz alta o texto da atriz durante as gravações para ela repetir as "falas".

Como dizem os especialistas da empresa Methodus de que a memória trabalha com imagens mentais, às quais são condensadas pelo nosso cérebro, este por sua vez grava muito mais facilmente as imagens, situações ou acontecimentos que fogem dos chamados padrões normais. Consideramos como padrões normais as imagens que podem ser rotineiras em nosso dia a dia ou aquelas que podem ser reais no nosso cotidiano. Portanto, a sociedade está alheia à leitura escrita. $\mathrm{O}$ mesmo acontece com as Pessoas Surdas, que se sentem melhor observando e reinterpretando a mesma língua de sinais brasileira no seu ato de interpretação.

Além disso, os argumentos recolhidos através das narrativas dos atores Surdos e dos autores que passaram esta experiência expuseram os fatores positivos na utilização da técnica de "reinterpretação" nos glosinais, assim como: a) diminuir a dificuldade de entendimento da segunda língua dos Surdos (Língua Portuguesa), segundo Fernandes (1990), a grande maioria das pessoas surdas, já escolarizada ou alfabetizadas funcionais, continuam demonstrando dificuldades tanto nos níveis fonológico e morfossintático, 
como nos níveis semântico e pragmático, devido ao processo histórico da discriminação e proibição da língua de sinais e da ausência da metodologia de ensino da língua portuguesa como segunda língua. A língua de Sinais Brasileira, como a primeira língua, é o instrumento funcional e usual de comunicação e de entendimento; b) diminuição da dependência, na área de psicologia, dependência emocional é um estado no qual a pessoa sente-se totalmente dependente de outra pessoa para que possa sentir-se segura e funcionar adequadamente. $\mathrm{O}$ dependente emocional acredita que a presença e atenção constantes de outra pessoa são necessárias para o seu bem-estar, segurança pessoal e de comunicação; c) custo e tempo - Os custos da qualidade de tradução da glosa face aos poucos benefícios resultantes da transmissão (tradução da língua portuguesa em texto para língua de sinais brasileira sinalizada). A solução com qualidade e da demanda tempo mais hábil é o uso dos tradutores e leitores Surdos das duas línguas (portuguesa e de sinais) presentes no ato de tradução; d) desestabilizar o uso da palavra por palavra - é uma das maneiras de evitar a glosa, pela sua grande influência na tradução que consistia em copiar a palavra da língua portuguesa em que os intérpretes ou profissionais tentam usar as palavras escritas no texto para repassar as informações às pessoas Surdas em outras línguas.

A comunidade Surda, privada da audição e do controle do ouvintismo, que segundo Skliar (1998), poderemos parodiar a ideologia dominante que se trata de um conjunto de representações das Pessoas Surdas, a partir do qual o Ouvinte está obrigado a olhar-se e a narrar-se como se fosse Surdo, através das percepções que legitimam as práticas de traduções / interpretações habituais, assim como acontece com os intérpretes e tradutores de língua de sinais.

\section{4) Conclusão}

Concluímos que a tradução / interpretação, se compreendida como uma linguística legítima apresenta uma gama de características singulares. Entre essas singularidades, encontra-se a língua de sinais, que é uma língua visual.

Entretanto, Skliar (2001) comenta que muitas vezes a caracterização dos surdos enquanto sujeitos visuais ficam restritas a uma capacidade cognitiva e/ou linguística de compreender e de produzir informação em língua de sinais. Este autor salienta que a experiência visual dos surdos envolve para além das questões linguísticas, todo tipo de significações comunitárias e culturais, portanto, a surdez significa, como experiência visual, a presença da língua de sinais, a produção de uma cultura que prescinde do som, entre outras.

Pensar nas comunidades surdas hoje significa, de acordo com Miranda (2001, p. 22): "ter em conta a representação das diferenças culturais, históricas e de identidade". Para o 
autor, as representações de diferença que se engendram no seio da comunidade surda encontram raízes na experiência visual, a partir da língua, das estratégias de interação sociocultural e das representações de mundo surdo e de mundo ouvinte.

De início, convém comentar que a oficialização da Língua de Sinais Brasileira ocasionou implicações em um dos diversos aspectos, no caso do uso da língua de sinais brasileira e sua tradução / interpretação: o Decreto $\mathrm{n}^{\circ} 5.626$ que considera como tradutor e intérprete da língua de sinais e da língua portuguesa aquele que interpreta de uma língua fonte para outra língua alvo. Segundo tal decreto, a formação desse intérprete deve efetivar-se por meio de curso superior de Tradução e Interpretação, com habilitação em Língua de Sinais Brasileira / língua portuguesa. Essa formação permite que o intérprete da língua de sinais brasileira atue na educação infantil, na educação fundamental e na universidade.

No entanto, convém ressaltar que, no Brasil, o intérprete encontra possibilidades restritas para o seu exercício profissional, com remuneração digna e fácil acesso a cursos referentes à sua área de atuação, os quais são geralmente ofertados nos grandes centros urbanos (PIRES e NOBRE, 2000). Estas autoras, por essas razões, esclarecem que ainda existe pequeno o número de pessoas habilitadas para cumprir essa função. Desta forma, os contextos educacionais, que efetivamente contam com a prática de intérpretes em sala de aula, são limitados, principalmente, no ensino fundamental e universitário.

Como acontece em outras situações com o mesmo problema de tradução, acreditamos que é necessário que se pense na surdez não como diversidade ou fenômeno transitório. A tradução / interpretação existente necessita de uma proposta pedagógica nova, pensada para suas singularidades linguísticas e culturais. Os surdos não querem adaptações, não querem ser dependentes como simulacros de ouvintes. $\mathrm{O}$ uso da técnica e mecanismo de Glosinais são as experiências comprovadas de que os Surdos querem a independência no uso da voz e da responsabilidade dos usos de sinais, sem interferência da língua portuguesa em sua volta.

Nesse sentido, acreditamos que a tradução / interpretação através da visualidade é uma área de investigação, pesquisa e discussão que deve ser mais bem aproveitada pelos profissionais da tradução / interpretação e pela comunidade surda. A leitura de "sinais" e as estratégias visuais de leitura e interpretação sinalizada devem ser incentivadas nos laboratórios e utilizadas, não apenas como ferramentas de apoio, nas ocupações do espaço central na organização do ensino de tradução / interpretação, participações dos novos tradutores no mercado de trabalho para imergir ${ }^{\text {vi }}$ os sinais. 
${ }^{\mathrm{i}}$ É o novo conceito para denominar Glosa, que segundo SOUZA (2010), consiste em uma interlíngual escrita em português do texto em Libras que confere suporte ao procedimento de tradução. Distinta da comunidade Surda, Glosinais consiste em uma intralíngual sinalizada em língua de sinais brasileira visualizada em língua de sinais brasileira visualizada que confere suporte ao procedimento de tradução, acrescentando comentários, casos reais e outros. É realizado através de uma tradutora que fica atrás da câmera repassando as informações da língua portuguesa escrita para língua de sinais brasileira. Em consonância do autor SOUZA (2010, apud STONE, 2009:90), "trata-se de um tipo de tradução que pode acontecer, por exemplo, diante de câmeras de televisão, e conta com a presença de tradutores durante a execução de atividade tradutória". É através dela que podemos esclarecer, para o leitor visual, ajudar mais a reflexão através da aquisição de conhecimento.

ii Glosa, que segundo SOUZA (2010) consiste em uma interlíngua escrita em português do texto em Libras que confere suporte ao procedimento de tradução, criado pelo STONE (2009).

iii É a nova modalidade da comunicação e esse designa como usuário da língua de sinais brasileira ou usa outras línguas visuais pelo fato da Língua de Sinais Brasileira possuir modalidade viso-gestual ou visoespacial.

${ }^{\text {iv }}$ Um teleprompter ou teleponto é um equipamento acoplado às câmeras de filmar que exibe o texto a ser lido pelo apresentador.

v Aportuguesada é quando é utilizado na cópia de uma palavra literal da língua portuguesa em cima da língua de sinais brasileira e ela acaba perdendo o seu significado e essência da tradução.

${ }^{\text {vi }}$ A imersão dos sinais ocorre quando os interessados em aprender a língua de sinais e vão introduzindo a cultura, estrutura gramatical, conhecimento linguístico, relação de poder, competência linguística e acabarão se estabelecendo nas suas "entranhas linguísticas" por outras vias diferentes da língua oral.

\section{5) Referência bibliográficas}

ALBERTI, Verena. Manual de história oral. Rio de Janeiro: Editora FGV, 2005.

BRASIL. Lei $\mathbf{n}^{\mathbf{0}} \mathbf{1 2 . 3 1 9}$, de $1^{\circ}$ de setembro de 2010. Regulamenta a profissão de Tradutor e Intérprete da Língua Brasileira de Sinais - LIBRAS. Brasília, 2010.

Decreto $\mathbf{n}^{\mathbf{0}} \mathbf{5 . 6 2 6}$ de 22 de dezembro de 2005. Regulamenta a Lei $\mathrm{n}^{\mathrm{o}}$ 10.436, de 24 de abril de 2002, Dispõe sobre a Língua Brasileira de Sinais - Libras. Brasília, 2005.

Lei $\mathbf{n}^{\mathbf{0}}$. 10.436, de 24 de abril de 2002. Dispõe sobre a Língua Brasileira de Sinais - LIBRAS e dá outras providências. Brasília, 2002.

CASTRO, Nelson Pimenta de. A tradução de fábulas seguindo aspectos imagéticos da linguagem cinematográfica e da língua de sinais. Dissertação (Mestrado) Universidade Federal de Santa Catarina, Centro de Comunicação e Expressão. Programa de Pós-Graduação em Estudos da Tradução. Florianópolis, 2012.

LACERDA, C.B.F. O Intérprete educacional de língua de sinais no Ensino Fundamental: refletindo sobre limites e possibilidades. In: Letramento e Minorias. LODI, A. C. B.; HARRISON, K. M. P.; CAMPOS, S. R. L. e TESKE, O. (Org.). Porto Alegre: Mediação, 2002.

LIMA, Paulo Gomes. Formação de Professores: Por uma ressignificação do trabalho pedagógico na escola. EDUFGD. 2010. 
MASUTTI, M. L. Tradução cultural: desconstruções logofonocêntricas em zonas de contato entre surdos e ouvintes. Tese de Doutorado em Literatura, UFSC, 2007.

MIRANDA, Wilson de Oliveira. Comunidade dos surdos: Olhares sobre os contatos culturais. Dissertação (Mestrado em Educação). Universidade Federal do Rio Grande Do Sul. Faculdade de Educação, Porto Alegre, 2001.

PEREIRA, Maria Cristina Pires e FRONZA, Cátia de Azevedo. Proficiência lingüística e fluência em língua de sinais: uma necessária revisão teórica. Universidade do Vale do Rio dos Sinos. s/d

QUADROS, R. M. O tradutor e intérprete de língua brasileira de sinais e língua portuguesa. Secretaria de Educação Especial; Programa Nacional de Apoio à Educação de Surdos. Brasília: MEC/ SEESP, 2004.

ROSA, A. S. Entre a visibilidade da tradução da língua de sinais e a invisibilidade da tarefa do intérprete. Petrópolis/RJ: Editora Arara Azul, 2005.

SOUZA, S. X. Performances de tradução para a Língua Brasileira de Sinais observadas no curso de Letras Libras. Dissertação. Estudos de Tradução. UFSC: Florianópolis. 2010.

SKLIAR, Carlos. Um olhar sobre o nosso olhar acerca da surdez e das diferenças. In: A surdez: um olhar sobre as diferenças. Porto Alegre: Editora Mediação, 1998.

Perspectivas políticas e pedagógicas da educação bilíngue para surdos. In: SILVA, Shirley; VIZIM, Marli. Educação Especial: múltiplas leituras e diferentes significados. Campinas: Mercado de Letras/ALB, 2001.

SITES:

Methodus - http://www.leituradinamica.net/ 